\title{
Formação de intérpretes versus ofício de tradutores públicos e intérpretes comerciais no Brasil: um estudo de caso no Estado do Ceará
}

\author{
Ananda Badaró de Athayde Prata \\ anandabadaro@gmail.com \\ Universidade Federal do Ceará, Fortaleza, Brasil
}

\author{
Tito Lívio Cruz Romão \\ cruzromao@terra.com.br \\ Universidade Federal do Ceará, Fortaleza, Brasil
}

\begin{abstract}
Resumo
No Brasil, quase todas as Juntas Comerciais estaduais selecionam, mediante concursos públicos, tradutores públicos e intérpretes comerciais (TPICS). Não há, todavia, nenhuma exigência de formação prévia em tradução/ interpretação para os candidatos inscritos nos concursos. Segundo Wyler (2003), desde o Brasil-Colônia a tradução/interpretação pública sempre esteve presente no país. Somente a partir dos anos 1950, essa disciplina passou a ser objeto de pesquisa da Linguística e, posteriormente, dos Estudos da Tradução. Para classificarem a interpretação especificamente, Mikkelson (2009), Pagura (2001) e Pöchhacker (2004) recorrem a diferentes critérios, considerando os contextos em que ela se realiza e o modo de trabalho utilizado pelos intérpretes. Visando a delinear o perfil da formação dos TPICs no Ceará, neste trabalho primeiramente se traçará um breve histórico do ofício de TPICs no Brasil e da legislação pertinente; depois serão comentados os resultados de uma pesquisa com 17 perguntas que foi aplicada a TPICs cearenses sobre sua formação e atuação profissional. O resultado da pesquisa apontou uma alta taxa de respostas: $62,26 \%$. Conforme os dados, $81,8 \%$ dos TPICs não possuem formação em interpretação, embora $75,8 \%$ atuem como intérpretes. Em sua totalidade, os resultados permitem uma reflexão sobre que medidas de formação profissional básica e/ou continuada se poderiam recomendar para que possa haver mudanças nesse quadro.
\end{abstract}

Palavras-chave: Estudos Aplicados da Tradução, tradutores públicos, intérpretes comerciais, formação profissional no Brasil.

1 Este artigo resume algumas das ideias centrais contidas na dissertação de Mestrado defendida em 2017 por Ananda Badaró de Athayde Prata, sob a orientação do Prof. Dr. Tito Lívio Cruz Romão no Programa de Estudos da Tradução (POET) da Universidade Federal do Ceará. 


\title{
Interpreter training programs versus the office of sworn translators and commercial interpreters in Brazil: a case study in the State of Ceará
}

\begin{abstract}
In Brazil, almost all the state Commercial Boards select sworn translators and interpreters (TPICs) by means of public tenders. However, there are no requirements for the applicants concerning previous qualification in translation/interpreting. According to Wyler (2003), since Colonial Brazil, public translation/interpreting has always been present in the country. Only in the 1950s, interpreting started to be an object of study in the field of Linguistics and, later, of Translation Studies. To classify particularly the field of interpreting, Mikkelson (2009), Pagura (2001) and Pöchhacker (2004) resort to different criteria, considering the contexts in which interpreting is performed and the interpreters' working modes. With views of delineating the profile regarding sworn translators' qualification in interpreting in the state of Ceará (Brazil), this work will outline a brief historical panorama of this profession in Brazil and its respective legislation. Next, the results of a questionnaire which was applied to sworn translators in Ceará with 17 questions about their working practice and professional qualification will be discussed. There was a high rate of answers: $62,26 \%$. According to the data, $81,8 \%$ of the sworn translators do not hold any qualifications in interpreting, although $75,8 \%$ of them work as interpreters. As a whole, these results allow us to reflect upon which measures could be recommended concerning basic and/or continuing professional trainings that could help to change this reality.
\end{abstract}

Keywords: Applied Translation Studies, sworn translators, commercial interpreters, professional training in Brazil.

\section{Formation d'interprètes par opposition au métier de traducteur public et d'interprète commercial au Brésil : une étude de cas dans l'État du Ceará}

\section{Résumé}

Au Brésil, presque toutes les chambres de commerce d'État sélectionnent des traducteurs et des interprètes commerciaux publics (TPIC) dans le cadre d'appels d'offres publics. Il n'y a toutefois aucune exigence de formation préalable en traduction/interprétation pour les candidats inscrits à des concours. Selon Wyler (2003), depuis la période coloniale au Brésil, la traduction/l'interprétation publique a toujours été présente dans le pays. Ce n'est que dans les années 1950 que cette discipline a fait l'objet d'études en linguistique, puis en traduction. Pour classer cette activité, Mikkelson (1999), Pagura (2001) et Pöchhacker (2004) ont recours à des critères différents, en tenant compte des contextes dans lesquels l'interprétation est effectuée et du mode de travail des interprètes. Dans le but d'esquisser le profil de la formation des TPIC au Ceará, cet article retracera d'abord un bref historique du bureau des TPIC au Brésil et de la législation pertinente, puis les résultats d'une recherche avec 17 questions appliquées aux TPIC du Ceará sur leur formation et leur performance professionnelle seront commentés. Le résultat de l'enquête a montré un taux de réponse élevé : 62,26\%. Selon les données, 81,8\% des TPIC n’ont pas de formation en interprétation, bien que 75,8\% travaillent comme interprètes. Dans l'ensemble, les résultats permettent de réfléchir aux mesures de formation professionnelle initiale et/ou continue qui pourraient être recommandées afin d'apporter des changements dans ce cadre.

Mots-clés : Études appliquées de traduction, traducteurs publics, interprètes commerciaux, formation professionnelle au Brésil. 
A expressão "Tradutor Público" é em si perfeita, expressando modernamente o que pratica o seu titular. A aposição, "Intérprete Comercial", apenas resguarda a ligação com o antigo título, que passou a ser tradicional.

Armando de Salmont Campbell

\section{Introdução}

O presente artigo insere-se na área de Estudos da Tradução, mais especificamente no âmbito da interpretação, e aborda a questão da formação de tradutores públicos e intérpretes comerciais (doravante: TPICs) do Estado do Ceará nessa área do conhecimento. Este trabalho é fruto da dissertação de mestrado intitulada O papel da formação em interpretação dos tradutores públicos e intérpretes comerciais no Estado do Ceará, defendida no âmbito do Programa de Pós-Graduação em Estudos da Tradução (POET), na Universidade Federal do Ceará, em Fortaleza, no ano de 2017. A ideia que levou à pesquisa de mestrado teve sua origem ao se constatar a necessidade de discutir a qualificação profissional de TPICs e de traçar o perfil da classe profissional responsável pelo exercício deste ofício público. Tal necessidade, por seu turno, surgiu a partir de leituras realizadas sobre temas relacionados à interpretação em geral e, de modo particular, à atuação dos TIPCS e aos requisitos profissionais deste ofício no Brasil e em outros países. Pôde-se então constatar a falta de literatura sobre esse tema no tocante a essa situação específica em nosso país como um todo e, de modo restrito, no Estado do Ceará.

Os TPICs, mais conhecidos como tradutores juramentados ou tradutores públicos, são habilitados pelas Juntas Comerciais das respectivas unidades federativas do Brasil, inclusive o Distrito Federal, por meio de concurso público para o provimento de vagas destinadas ao ofício. Ao serem aprovados em concurso pú- blico específico, os TPICs recebem tão-somente um aval para realizarem traduções com fé pública, o que significa que a tradução é fiel ao documento original e pode ser utilizada como elemento comprobatório junto a instituições públicas e privadas. A mesma fé pública vale tanto para sua atuação como tradutores quanto como intérpretes. Frise-se que o ofício de TPICS não constitui cargo público com vínculo empregatício, visto vez que esse profissional não recebe salário ou aposentadoria de nenhum órgão público, ganhando unicamente por cada serviço prestado. Os valores cobrados por lauda traduzida e por atuação como intérprete, denominados emolumentos, são estabelecidos pela Junta Comercial de cada unidade da Federação. Conforme o Artigo 17 do Decreto 13.609, que foi promulgado em 21 de outubro de 1943 e que regulamenta o ofício, aos TPICs compete uma série de tarefas, para além de sua atividade precípua. Em primeira linha, tal atividade consiste em interpretar e verter verbalmente, na língua nacional, as respostas ou depoimentos dados em Juízo por estrangeiros não fluentes no vernáculo, sempre que estes precisem ser interrogados como partes principais ou ainda ser arrolados como testemunhas ou informantes, perante um juiz ou também no foro extrajudicial, em repartições públicas dos diferentes níveis administrativos etc. (Decreto $\mathrm{n}^{\circ} 13.609,1943$ ). Dentre as outras tarefas, o decreto estipula, por exemplo, que eles estão igualmente aptos a passar certidões e a traduzir para a língua vernácula quaisquer livros e demais documentos redigidos originalmente em uma língua estrangeira, que precisem ser apresentados em Juízo ou perante uma repartição de qualquer nível da administração pública. Por fim, o decreto também autoriza os TPICS a intervirem como avaliadores de traduções que tenham suscitado qualquer dúvida, após terem sido apresentadas a uma autoridade pública. Essa faculdade também inclui examinar quaisquer 
traduções de documentos relativos a despachos alfandegários, que, feitas por corretores de navios, venham a ser impugnadas por possível falta de exatidão. $\mathrm{O}$ mesmo procedimento também abrange a possível impugnação - também por falta de imprecisão - de traduções feitas por ocupantes de cargos públicos na função de tradutores e intérpretes (Decreto $\left.\mathrm{n}^{\mathrm{o}} 13.609,1943\right)$.

Dentre os requisitos para se prestar o concurso, os dispositivos legais apontam: a) ter no mínimo 21 anos; b) não ser negociante falido ou habilitado; c) ser cidadão brasileiro nato ou naturalizado; d) não ter sido processado nem condenado por crime que implique na demissão de cargo público ou na inabilitação para exercê-lo; e) residir por mais de um ano no estado da Federação em questão; f) estar em dia com o serviço militar (no caso de candidatos homens) e eleitoral; g) comprovar a identidade; h) ter sido aprovado nos exames. Ressalte-se que, talvez por essas exigências mínimas ainda remontarem ao primeiro governo do presidente Getúlio Vargas, ou seja, à década de 1940, os padrões de qualificações e competências demandados para o exercício do ofício de тPICs ainda se mostram bastante defasados. Não se requer, por exemplo, uma formação superior ou técnica na área específica de tradução - e muito menos de interpretação - nem na área mais abrangente de Letras e tampouco em quaisquer outros cursos de nível superior. Da mesma forma, não se exige sequer um certificado de proficiência na língua estrangeira para a qual o candidato deseja inscrever-se. Por conseguinte, a falta de exigências voltadas para disciplinas ou áreas de estudos diretamente ligadas ao ofício de TPICs faz com que o público-alvo desses concursos também seja composto por candidatos com formação -superior ou não- em qualquer área do conhecimento e com proficiência pelo menos prática em um dos idiomas-alvo da seleção. Portanto, é possível que a atuação profissional de TPICs concursados venha a diferir daquela exercida por tradutores-intérpretes com formação específica nas áreas de tradução e interpretação, o que eventualmente pode gerar dificuldades nas práticas profissionais.

Com relação ao cotidiano de trabalho de TPICs, esses profissionais se deparam com os mais diversos gêneros textuais, dentre os quais se podem mencionar: documentos públicos $\mathrm{e}$ privados diversos, tais como certidões de nascimento, casamento e óbito, sentenças e outros documentos de processos judiciais, contratos e quaisquer documentos estrangeiros que precisem de comprovação no Brasil ou de brasileiros que precisem de comprovação no exterior. Além disso, há uma outra parte das atribuições dos TPICs que atinge o cerne da questão aqui discutida: a realização de tarefas de interpretação em contextos como cerimônias de casamento civil, atos de lavraturas de escrituras públicas, audiências com juízes e outras autoridades públicas, apreensões de presos estrangeiros na polícia federal, entre outras situações em que se exija a atuação de intérpretes públicos. Visto que os profissionais aprovados nos concursos supramencionados podem ter formações acadêmicas bastante diversificadas, entendemos ser válido questionar se possuem alguma formação em tradução e/ ou interpretação para realizarem suas tarefas. É igualmente lícito especular sobre como TPICs sem formação - ou prática profissional em interpretação se sentem em situações em que devam exercer a função de intérprete.

Portanto, diante do contexto supracitado, nossa pesquisa teve como objetivo verificar, no tocante aos TPICs em atuação no Estado do Ceará no período da realização da pesquisa com questionários (2015-2016), os seguintes aspectos: a) se possuem formação em interpretação; b) a frequência com que se deparam com 
situações em que precisam da competência interpretativa para a execução de seu ofício; e, por fim, c) quando não possuem formação específica em interpretação, como adquirem as habilidades necessárias para realizar suas diversas modalidades de interpretação.

\section{O ofício de TPICs no Brasil}

Uma vez apresentadas a contextualização e a justificativa da pesquisa por nós realizada, gostaríamos agora de abordar alguns aspectos históricos atinentes à atividade de TPICs em nosso país desde o período do Brasil Colônia até a atualidade. Ao longo desse panorama histórico, também serão discutidos alguns aspectos relativos à legislação brasileira acerca do ofício de tradutores e intérpretes no âmbito público.

\subsection{A atividade durante o Brasil Colônia}

Desde seus primórdios, a tradução juramentada no Brasil teve uma estreita relação com a interpretação. Segundo as considerações de Wyler (2003), a atividade teve início no Brasil concomitantemente com o achamento, pelos portugueses, das terras denominadas de Pindorama pelos indígenas. Veja-se o que afirma a autora:

O lingua, como era chamado então o tradutor em língua oral (ou intérprete), foi imediatamente institucionalizado pelos colonizadores europeus. O tradutor em língua escrita só iria ser contratado pela instituição colonial em 1808, com a fundação da Impressão Régia. (Wyler, 2003, p. 29-30)

Tal necessidade de institucionalização deveu-se ao fato de os portugueses terem se deparado com uma riquíssima variedade linguística em terras brasileiras, dada a grande quantidade de tribos indígenas presentes no território que haviam ocupado. Oliveira (2006, p. 69) destaca que a primeira referência à profissão, em Portugal, apresenta-se como um alvará com força de lei publicado em 4 de janeiro de 1754, regularizando os ordenados dos Secretários de Estado e os de seus oficiais. O autor afirma que, entre os oficiais maiores, estava o "oficial de línguas", que recebia um ordenado anual de um conto de réis (CLP, 1830 apud Oliveira, 2006). Após a publicação do referido alvará, que somente aconteceu em $1^{\circ}$ de abril de 1796, quando foram aprovados os Estatutos da Academia Real dos Guardas Marinhas, foi estabelecido, em seu Título vIII, a figura do "Traductor de Línguas", cujas atribuições consistiam em traduzir os documentos dirigidos ao Conselho em qualquer dos idiomas apontados no Artigo 2, entender dos assuntos e dominar a comunicação.

\subsection{A atividade durante o Brasil Império}

O segundo decreto, inserido no contexto do Brasil Império, data de 9 de dezembro de 1823 e dispõe a nomeação de Eugenio Gildmester como "traductor jurado da Praça e intérprete da Nação" (Wyler, p. 43) e o recebimento de emolumentos das partes pelas traduções, com o valor de $1 \$ 100$ réis por meia folha. $O$ decreto representa a primeira vez em que o ofício de tradutor é associado ao de intérprete. Outro fato memorável é que o cargo de "tradutor jurado da praça e intérprete da nação" não estava vinculado a nenhum órgão oficial. Outro evento relatado por Wyler (2003, p. 43) data do final da década de 1850 , e refere-se ao seguinte:

$$
\begin{aligned}
& \text { [...] o Código e o Regulamento comerciais determi- } \\
& \text { naram que os documentos passados em países es- } \\
& \text { trangeiros só seriam considerados competentemen- } \\
& \text { te traduzidos em língua nacional quando a tradução } \\
& \text { fosse feita por um intérprete público nomeado pe- } \\
& \text { los Tribunais do Comércio da capital do império. }
\end{aligned}
$$

Tal determinação marca o início do processo de transição para o status da tradução juramentada como é conhecida no Brasil dos dias atuais. Em 
seguida, Wyler salienta que em 17 de novembro de 1851 foi lançado o Decreto Imperial $n^{\circ} 863$, definindo o regulamento para os intérpretes de comércio da Praça do Rio de Janeiro, delegando à instituição a nomeação desses profissionais e estabelecendo seus emolumentos junto ao Tribunal do Comércio da então capital do império. Os tradutores precisavam cumprir as mesmas condições que os comerciantes para serem instituídos no ofício. Ademais, era necessário comprovar o conhecimento prático de línguas estrangeiras e estar em dia com o pagamento dos impostos anuais. Uma circunstância digna de nota é que o exercício da profissão era explicitamente proibido às mulheres.

Outro fato evidenciado é o de que os Tribunais do Comércio foram extintos pelo decreto $\mathrm{n}^{\mathrm{o}}$ 2662, promulgado aos 9 de outubro de 1875 . Suas atribuições foram transferidas para as Juntas Comerciais, que foram estruturadas conforme o decreto $\mathrm{n}^{\circ}$ 596, de 19 de julho de 1890.

\subsection{A atividade no Brasil República}

Ao discorrer sobre o ofício de tradutores e intérpretes públicos e sua menção específica no Código Civil Brasileiro (СС) expedido em 1916, Campbell (1983, p. 111) destaca o artigo 140 do CCB, que dispõe o seguinte: "Art. 140 - Os escritos de obrigações redigidos em língua estrangeira serão, para terem efeitos legais no país, vertidos em português" (Lei $\mathrm{n}^{\circ}$ 3.071, 1916). Campbell também nos lembra que os artigos 1.632 e 1640 do mesmo CCB expõem que, no que concerne a testamentos, os testamentos públicos em hipótese alguma poderiam ser elaborados em língua estrangeira nem ser traduzidos, ao passo que os testamentos cerrados poderiam, após sua abertura, ser submetidos a uma tradução juramentada.

O autor ainda aponta que o Código de Processo Civil (CPC) de 1939, que vigorou até o ano de 1973, também contemplava a tradução pública. Em seu artigo 228, о CPC dispunha: "Não serão admitidos em Juízo documentos escritos em língua estrangeira, salvo se acompanhados de tradução oficial" (Decreto-lei n ${ }^{\circ}$ $1.608,1939)$. No artigo $791, \mathrm{n}^{\circ} 5$, do mesmo documento oficial, também é mencionada a questão da sentença estrangeira, que, a fim de ser homologada no Brasil, necessita estar acompanhada de tradução pública. Outro ponto abordado por Campbell (1983) refere-se à mudança do termo utilizado para designar a profissão:

\begin{abstract}
O antigo intérprete, de que falava a legislação do Império, teve sua designação mudada hodiernamente para Tradutor Público e Intérprete Comercial. Não se trata de duas funções dissociadas, mas um único título duplo de uma só função inseparável. A expressão Tradutor Público é em si perfeita, expressando modernamente o que pratica o seu titular. A aposição, Intérprete Comercial, apenas resguarda a ligação com o antigo título, que passou a ser tradicional. (Campbell, p. 111)
\end{abstract}

Conforme o exposto acima pelo autor, vemos, na expressão atualmente usada como designação dos TPICs, a palavra intérprete, que nos leva de volta àquela noção adotada no Brasil Império; por outro lado, sua junção ao termo comercial representa um retorno ao período em que os tradutores e intérpretes públicos exerciam sua atividade mormente no ambiente de comércio alfandegário. Seja como for, essa qualidade comercial foi-se perdendo ao longo dos anos, de modo que já não representa uma porção considerável das tarefas exercidas por TPICs. A regulamentação atual data de 21 de outubro de 1943, mediante o decreto 13.609 (1943), sancionado durante o governo do presidente Getúlio Vargas pelo então ministro do Trabalho, Indústria e Comércio, Alexandre Marcondes Machado Filho. Essa provisão designa o ofício de Tradutor Público e Intérprete Comercial, cuja nomeação é instituída 
mediante concurso público classificatório e regido pelas Juntas Comercias de cada estado ou pelos órgãos encarregados dos registros do comércio.

Dentre os requisitos necessários para candidatar-se ao concurso público, é possível enumerar, como reza a legislação atualmente vigente: a) ter mais de 21 anos completos; b) não ser negociante falido irreabilitado; c) ser cidadão brasileiro, nato ou naturalizado; d) não ter sido processado ou condenado por crime cuja pena importe em demissão de cargo público ou inabilitação para o exercer; e) residir por mais de um ano na praça onde pretenda exercer o ofício; f) estar quitado com o serviço militar; g) apresentar documento de identificação.

Vale destacar que foi apenas a partir dessa legislação aprovada em 1943 que o exercício da atividade de TPICs passou a ser igualmente estendido às mulheres.

\section{Questões teóricas sobre interpretação}

$\mathrm{Na}$ seção anterior, lançamos luz sobre algumas peças legislativas importantes para o estabelecimento do ofício de TPICs ao longo da história do Brasil, desde o período colonial e imperial, passando pelo estabelecimento da República, até os dias atuais. A análise da legislação possibilitou a compreensão do desenvolvimento do ofício no país, abrangendo aspectos como as atribuições dos profissionais, os requisitos para a realização do ofício e a avaliação das competências dos candidatos. Debateremos, a seguir, pontos relacionados ao conceito de interpretação, uma vez que a apreensão dos fundamentos desta área do conhecimento tem relação direta com a atuação de tPICs e, consequentemente, com o tema da pesquisa realizada.
Pöchhacker (2004, p. 9) define a interpretação "como uma atividade tradutória, uma forma especial de tradução" 2, adotando a noção proposta por Otto Kade (1968), que entendia interpretação como uma forma de tradução, na qual: a) "o texto-fonte é apresentado apenas uma vez e logo não pode ser revisado ou revisto; b) o texto-alvo é produzido sob pressão de tempo, com pouca oportunidade para correção e revisão". Pöchhacker ressalta que tal fato "justifica a caracterização geral da interpretação como um tipo imediato de atividade tradutória, realizada 'em tempo real' para uso imediato” (id.; p. 11). De forma concisa, uma definição formulada com base nos dois critérios de Otto Kade supramecionados, que remetem, portanto, ao caráter de imediaticidade do processamento do texto pelo intérprete, postula o seguinte: "interpretação é uma forma de tradução na qual uma primeira e última reprodução em outra língua é produzida com base em uma única apresentação de um enunciado em uma língua-fonte"3 (id; p. 11).

\subsection{Parâmetros e constelações}

Pöchhacker (2004) também adianta que, se observarmos o fenômeno por um prisma histórico, o critério mais evidente para a categorização da interpretação é o contexto social de interação - ou ambiente - no qual a atividade é realizada. Em seus primórdios, a interpre-

2 Neste artigo, as citações feitas a partir de Pöchhacker (2004) serão apresentadas em nossa tradução.

3 Apoiando-se nessa mesma ideia, Reiss \& Vermeer (1991, p. 8), ao lançarem sua Teoria do Escopo, entenderam que um critério distintivo entre tradução e interpretação é a "corrigibilidade"; asseveram que, no ato da interpretação, o resultado obtido pelo intérprete não permanece à disposição para que se façam correções, pois ou o texto de partida ou o texto de chegada ou ambos somente existem na modalidade oral, não se podendo recorrer ao material oral para refazer o ato de interpretação que acontece uma única vez. 
tação ocorria quando membros de diferentes comunidades linguísticas e culturais entravam em contato com algum objetivo em particular. Além dos contatos entre entidades sociais em vários ambientes intersociais, a comunicação intermediada era concebível também em sociedades plurilíngues. Neste caso, o autor refere-se à "interpretação em contextos intrassociais" (Pöchhacker, 2004, p. 13), que serão especificados a seguir, segundo a classificação apresentada pelo pesquisador austríaco.

\subsubsection{Parâmetros intrassociais e intersociais}

Pöchhacker (2004, p. 14) expõe que alguns dos primeiros contatos intermediados entre comunidades que falavam línguas diferentes tiveram como objetivo o comércio e o escambo de bens, ou seja, a intenção de fazer negociações, o que implicaria em reconhecer a interpretação de negócios como um tipo primitivo de interpretação. É possível depreender, com base na análise dessa prática, que a atividade foi evoluindo ao longo da história em diversos ambientes, desde primeiros contatos entre tribos distintas até negociações institucionalizadas, em relações intrassociais e intersociais.

Partindo dessa premissa, o autor propõe um espectro que se estende às esferas de interação supracitadas e reflete uma institucionalização crescente de contatos e comunicação. Esse espectro varia de contatos de expedição, como contatos exploratórios e trabalho missionário, que seriam "contatos isolados", passando por "transações comerciais e de negócios, militares e diplomáticas, chegando a contatos institucionais, da administração, da justiça e serviços públicos" (Pöchhacker, 2004, p. 15), o que atingiria a esfera intrassocial. Desse modo, quanto mais institucionalizado o contexto da interpretação, mais a atividade penderia para a esfera intrassocial.
Utilizamos o espectro dos parâmetros tipológicos propostos pelo autor, por entendermos que se trata de uma divisão didática e, ao distinguir os contextos da interpretação e suas modalidades linguísticas e modos de trabalho, categoriza o fenômeno de forma mais organizada, em vez de limitar a divisão apenas a tipos de interpretação.

\subsubsection{Interpretação de enlace}

Pöchhacker (2004, p. 16) cita a interpretação de enlace - também chamada de interpretação de negociações ou interpretação bilateral como um tipo praticado especialmente em negociações comerciais. Afirma igualmente que Gentile et al. (1996) fizeram uso do significado genérico de "liaison", expressando a ideia de conexão e ligação, e estenderam o termo a uma variedade de ambientes da interpretação, permeando as dimensões intra e intersociais. Já Hurtado Albir (2013, p. 637) define a interpretação de enlace como a "modalidade de tradução que consiste na tradução oral de conversas (políticas, de negócios etc.); costuma ter dupla direcionalidade (direta e inversa)" ${ }^{4}$.

\subsubsection{Interpretação legal}

Segundo Pöchhacker (2004, p. 14), à medida em que os povos foram se desenvolvendo, ou seja, transformando-se em sociedades mais abrangentes e complexas, foi-se tornando também possível "concebermos entidades multiétnicas e sociopolíticas nas quais a comunicação entre os sujeitos ou grupos pertencentes a comunidades linguísticas diversas necessitasse dos serviços de intérpretes". Também sublinha que, como uma consequência do estabelecimento de instituições para garantir a execução das leis, em especial nos territórios recentemente conquistados ou colonizados,

4. Nossa tradução. 
"os intérpretes eram contratados para assegurar que aqueles que não falavam a língua do país fossem levados em consideração". Logo, a interpretação legal - ou de tribunal - é um clássico exemplo de interpretação em um contexto institucional intrassocial. Pöchhacker (2004, p. 14) conclui que, "em muitas jurisdições, o que é frequentemente rotulado como interpretação de tribunal, inclui tanto a tradução juramentada de documentos quanto a interpretação em audiências parajudiciais e administrativas". Nesse sentido, também adianta que é possível "distinguir entre um conceito mais complexo de interpretação legal ou judicial e de tribunal", levando-se em conta os diferentes ambientes específicos.

Mikkelson ${ }^{5}$ (2009), por sua vez, afirma que "a interpretação de tribunal, também conhecida como interpretação legal, judiciária ou forense, refere-se a serviços fornecidos em tribunais de justiça e em casos legais de qualquer natureza". Utilizando-se dos conceitos propostos por Gonzalez et al. (1991), a autora afirma que "esse tipo de interpretação é realizado em um contexto legal, como um tribunal ou o escritório de um advogado, em que são realizados processos ou atividades relacionadas às leis". Também ressalta que a interpretação legal se subdivide, de acordo com o ambiente legal, "entre (1) interpretação parajudicial e (2) interpretação judicial”, sendo que esta última corresponderia ao que normalmente é considerado como interpretação de tribunal.

Outro ponto destacado por Mikkelson (2009) consiste na distinção que se faz, em algumas jurisdições - como, por exemplo, no estado norte-americano da Califórnia - "entre intérpretes de tribunal e intérpretes de audiencias administrativas". Enquanto os primeiros atuam

5. Os conteúdos extraídos de Mikkelson (2009) serão apresentados em nossa tradução. "em processos civis em tribunais de justiça", os segundos prestam serviços "em audiências conduzidas por juízes da legislação administrativa sob a tutela de órgãos do governo estadual".

\subsubsection{Interpretação comunitária}

Outro parâmetro discutido por Pöchhacker (2004, p. 15) é a "interpretação comunitária, ou interpretação do serviço público (como é chamada especialmente no Reino Unido) ou interpretação cultural (no Canadá)", que surgiu como um novo campo na área, tendo a interpretação médica e a interpretação legal como seus domínios institucionais mais significativos. A interpretação comunitária ganhou espaço em países com um grande número de imigrantes, considerando-se que estes precisam por um lado ter acesso ao mercado de trabalho e, por outro, também todo o aparato de serviços públicos que as instituições de países receptores de migrantes precisam administrar e fazer funcionar. Nesse contexto, o autor também sublinha que "enquanto países como a Suécia e a Austrália reagiram à demanda por serviços de interpretação para auxiliar os imigrantes na sociedade anfitriã, outros foram mais lentos em suprir tais necessidades de comunicação intrassociais". As mudanças mais marcantes no cenário da interpretação comunitária somente seriam sentidas entre as décadas de 1980 e 1990, "em face dos crescentes problemas de comunicação nas instituições do setor público (de saúde e serviços sociais)" (Pöchhacker, 2004, p. 15).

\subsection{Parâmetros tipológicos}

Em seu estudo sobre a interpretação, Pöchhacker (2004) não apenas apresenta uma classificação geral dos tipos de interpretação mediante a análise de parâmetros e constelações existentes, como também destaca critérios 
adicionais que ajudam a compor um inventário mais sistemático dos subtipos de interpretação. O autor aponta os seguintes critérios: modalidade linguística, modo de trabalho, direcionalidade, tecnologia e status profissional, dos quais, por questão de concisão, no presente trabalho abordaremos apenas os dois primeiros.

\subsubsection{Modalidade linguística}

Compartilhamos, em nossa pesquisa, a ideia defendida por Pöchhacker (2004, p. 17) de que "o termo 'interpretação' está geralmente associado à prática realizada em línguas orais, especialmente os idiomas oriundos da Europa ocidental mais utilizados em conferências e organizações internacionais". Todavia, não se pode negar a projeção que vem sendo adquirida pela "interpretação de línguas de sinais", dirigida à comunidade surda, o que no Brasil ganhou impulso notadamente após a a promulgação da Lei Presidencial $\mathrm{n}^{\circ} 10.436$ de 24 de abril de 2002 . Essa lei reconhece, em nosso país, a Língua Brasileira de Sinais (Libras) como meio legal de comunicação e expressão, além de recomendar outras providências; ademais, após sua regulamentação pelo Decreto $\mathrm{n}^{\mathrm{o}} 5.626$ de 22 de dezembro de 2005, a disciplina de Libras passa a fazer parte do currículo obrigatório tanto das escolas públicas quanto das universidades brasileiras. Considerando-se que as línguas de sinais se apresentam em uma modalidade espaço-visual, a terminologia mais precisa para definir a modalidade de interpretação específica dessa língua é interpretação sinalizada ou interpretação espaço-visual. Essa distinção faz-se necessária, porque as línguas de sinais são as línguas nativas dos surdos, os quais, por pertencerem à comunidade surda, possuem identidades culturais próprias e diferentes das encontradas nas comunidades ouvintes.
É pertinente observar que o objeto de estudo do presente artigo restringe-se apenas às línguas orais, uma vez que os idiomas com tradutores credenciados na Junta Comercial do Estado do Ceará (JUCEC) são apenas alemão, espanhol, francês, inglês e italiano; desta forma, a Língua Brasileira de Sinais (Libras) não faz parte desse rol. Nos contextos em que a interpretação em Libras é necessária, como depoimentos em juízo, apreensões e casamentos civis em que haja alguma pessoa surda envolvida, são nomeados intérpretes juramentados ad hoc, um procedimento que tem validade apenas para aquela situação específica. A mesma providência é igualmente tomada com relação a quaisquer outras línguas, para as quais não haja tradutores credenciados na JUCEC, como ocorre com mandarim, japonês, russo, hebraico etc.; o mesmo também pode se dar nos casos em que não haja momentaneamente TPICs disponíveis para uma das línguas constantes da lista de tradutores licenciados.

\subsubsection{Modos de trabalho}

Com relação ao modo de trabalho, Pöchhacker (2004, p. 18) acentua que, "da mesma forma que ocorria com a modalidade linguística, a interpretação, quando e na forma como era praticada em seus primórdios, não requeria maior sofisticação tecnológica até o surgimento de outro modo de trabalho". A grande mudança somente aconteceria na década de 1920, quando a tecnologia possibilitou o desenvolvimento de um equipamento de transmissão, viabilizando a atuação de intérpretes de forma simultânea. Foi a partir dessa evolução que se passou a fazer uma distinção entre "a interpretação consecutiva", realizada "após o texto-fonte ser enunciado na língua-fonte", e "a interpretação simultânea" realizada "ao mesmo tempo em que o texto na língua-fonte está sendo apresentado". Pöchhacker (2004, p. 18) também frisa que "a interpretação simultânea 
foi inicialmente implementada como simultânea-consecutiva". Em outras palavras, tratava-se da transmissão de duas ou mais interpretações consecutivas em diferentes línguas, o que normalmente se denomina interpretação relay.

\subsubsection{Interpretação consecutiva}

Ao entrar no âmbito das modalidades de interpretação, Pöchhacker (2004, p. 18) primeiramente aborda a interpretação consecutiva, fazendo a seguinte ressalva inicial: "Como a interpretação consecutiva não pressupõe uma duração específica do ato original do discurso, ela pode ser concebida como um contínuo que varia desde a tradução de breves declarações até o proferimento de discursos inteiros". Sujeita ao estilo de trabalho e às habilidades de memória do intérprete, mas igualmente a um número de variáveis situacionais - tais como a apresentação de slides pelo palestrante, além de pausas e digressões em sua fala -, a interpretação consecutiva de discursos mais longos envolve a tomada de notas, tal como foi desenvolvida pelos pioneiros da interpretação de conferências sobretudo a partir de meados do século xx (cf. Romão, 2014).

\subsubsection{Interpretação simultânea}

De acordo com Pagura (2002), a intepretação simultânea é a modalidade mais amplamente utilizada hoje em dia. Nesse caso, os intérpretes, preferencialmente sempre em duplas, trabalham isolados em uma cabine com vidro que lhes permitir ver o orador, além de poderem ouvir o discurso e as demais falas com fones de ouvido. Ao processarem a mensagem, expressam-na na língua de chegada por meio de um microfone ligado a um sistema de som que leva sua fala até os ouvintes, que portam fones de ouvido ou receptores semelhantes a rádios portáteis.

\subsubsection{Tradução oral à prima vista}

Uma outra modalidade de interpretação que merece destaque, sendo inclusive treinada em cursos de formação de intérpretes, é a tradução oral à prima vista. Pöchhacker (2004, p. 19) considera-a um tipo especial de interpretação simultânea, na qual um texto escrito é traduzido à medida que o intérprete o lê, ou seja: "a produção do texto-alvo do intérprete é concomitante não à elocução do texto-fonte, mas à percepção visual que o intérprete tem do texto escrito". É importante lembrar que, em determinadas situações, o intérprete acaba lançando mão de uma combinação de modalidades de interpretação, podendo, como bem sublinha Pöchhacker (2004, p. 19), "mesclar a tradução oral à prima vista com a consecutiva, chegando até mesmo a lembrar a modalidade intermitente, com uma margem considerável [de tempo] para revisão e correção [de possíveis erros]".

\subsubsection{Interpretação intermitente}

No Brasil, Pagura (2002, p. 212), tece as seguintes considerações sobre a interpretação intermitente:

\footnotetext{
A modalidade intermitente (ou "sentence-by-sentence", ou ainda "ping-pong”) não é comumente estudada por pesquisadores da área, nem é utilizada por profissionais em eventos de caráter internacional. É vista mais freqüentemente em reuniões nas quais se pede a uma pessoa que fala as duas línguas, via de regra sem qualquer treino em interpretação, para que se coloque ao lado de um palestrante estrangeiro e traduza o que ele está dizendo. O palestrante fala uma ou duas frases curtas e faz uma pausa para que as suas sentenças sejam traduzidas para o idioma da platéia. [...]. É comum algumas pessoas confundirem essa modalidade de interpretação com o que os profissionais chamam de consecutiva [...].
}

Essa modalidade, justamente por não ser requerida com frequência em grandes reuniões, pode facilmente fazer parte do trabalho de 
TPICs que precisem atuar como intérpretes em reuniões com pequenos grupos, em visitas e/ ou audiências (por exemplo em cartórios, em repartições públicas etc.) etc., em que o intérprete ouça apenas uma frase ou duas e já expresse na outra língua o conteúdo que o interlocutor proferiu.

A seguir, serão apresentados alguns aspectos metodológicos que foram úteis à consecução da pesquisa que deu origem a este artigo, notadamente visando à realização da coleta de dados e de sua posterior análise e avaliação.

\section{Aspectos metodológicos}

A pesquisa realizada foi de natureza quantitativa e exploratória e de caráter bibliográfico e documental, visto que foi feita uma revisão bibliográfica referente à história do ofício de TPICs e à interpretação como atividade prática (com ênfase centrada na atuação dos profissionais) e como área específica de estudo e de ensino (Estudos da Tradução em geral e Estudos da Interpretação em particular). $\mathrm{Na}$ primeira etapa, foi necessário consultar diversas obras nacionais e estrangeiras, em busca de documentos, relatos, textos de leis etc. que pudessem ser úteis para uma melhor compreensão das temáticas supracitadas e, por conseguinte, decisivos na elaboração dos questionários, alvo maior da pesquisa. Além da revisão bibliográfica, igualmente fez parte da estrutura investigativa a consulta acurada a diferentes documentos, tais como editais anteriores lançados pela JUCEC (p. ex. o Edital $n^{\circ}$ 001/2010, de 07 de outubro de 2010), textos legais brasileiros (Decreto $\mathrm{n}^{\mathrm{o}} 13.609$ de $21 \mathrm{de}$ outubro de 1943, diversos textos de leis, decretos e disposições contidos nas $\mathrm{CLB}^{6}, \mathrm{CLP}^{7} \mathrm{e}$

6 Coleções de Leis do Brasil.

7 Coleções da Legislação Portuguesa.
$\mathrm{CLIB}^{8}$, dentre outros), o estatuto da Associação Cearense de Tradutores Públicos e Intérpretes Comerciais (ACETESP) etc.

Portanto, para atingir os objetivos propostos durante o processo, foram utilizados os seguintes procedimentos:

a. leitura e análise do referencial teórico relacionado aos conceitos de interpretação, nomeadamente definições e reflexões pertinentes ao desenvolvimento do estudo;

b. elaboração de um questionário referente à formação dos TPICS, ao conhecimento das modalidades de interpretação e aos contextos com os quais esses profissionais se deparam em seu ofício;

c. aplicação do questionário aos TPICs, por meio da qual foi feita a coleta dos dados, observando-se aspectos relevantes para a construção de um perfil da classe profissional;

d. avaliação e análise dos dados catalogados, a fim de estabelecer possíveis esclarecimentos sobre questões levantadas ao longo da pesquisa.

\subsection{Local e período de realização do estudo}

O estudo em questão foi conduzido na cidade de Fortaleza, capital do estado do Ceará, Brasil, entre os anos de 2015 e 2016. Os dados foram gerados e coletados mediante um questionário online, tendo como suporte a ferramenta Google Forms.

\subsection{Participantes do estudo}

Os Tradutores Públicos e Intérpretes Comerciais licenciados pela Junta Comercial do Es-

8. Coleções de Leis do Império do Brasil. 
tado do Ceará foram os sujeitos envolvidos na pesquisa, em especial - embora não necessariamente apenas - os membros da ACETESP, entidade que, em forma de associação de classe, representa os TPICs do Estado do Ceará, e cujo presidente prontamente atendeu à solicitação da pesquisadora. No momento da coleta de dados, o Ceará contava com 60 TPICs concursados e empossados pela JUCEC. Entretanto, o questionário objeto desta pesquisa somente pôde ser aplicado a 53 desses profissionais, pois não foi possível ter acesso aos endereços eletrônicos de todos os TPICs listados pela JUCEC em seu portal, já que sete dentre eles não os disponibilizaram.

\section{O perfil da classe profissional dos TPICS no Ceará}

Acima foram delimitados os aspectos de caráter metodológico da pesquisa relacionados à natureza, ao local e aos participantes do estudo. A seguir, detalharemos questões relativas ao instrumento de coleta de dados utilizado na pesquisa, a saber, o questionário gerado a partir da ferramenta Google Forms. Em uma etapa posterior, apresentaremos, avaliaremos e discutiremos uma seleção de dados extraídos da coleta realizada durante a pesquisa.

\subsection{Apresentação, avaliação e discussão dos dados coletados}

Como descrito anteriormente, o questionário on-line foi aplicado aos tradutores públicos registrados na JUCEC com o suporte da ferramenta Google Forms. No momento da pesquisa, a JUCEC apresentava em seu site a seguinte distribuição de TPICs registrados por idioma: 4 de alemão, 11 de espanhol, 9 de francês, 30 de inglês e 6 de italiano, totalizando 60 profissionais. Entretanto, reiteramos que sete dos tradutores não disponibilizaram seus contatos de e-mail no site da instituição. Desse modo, o questionário foi aplicado a 53 profissionais, dentre os quais 33 o responderam, perfazendo $62,26 \%$ do total de TPICs, o que se traduz em uma alta taxa de respostas. Abaixo serão apresentados os dados obtidos a partir de uma seleção de questões propostas aos TPICs no referido questionário. Como este artigo é apenas um recorte de um trabalho mais extenso, a saber, o texto da dissertação de mestrado já mencionada, apresentaremos apenas os dados diretamente relacionados à formação dos TPIcs (questões 5 a 14).

\subsection{1 Área de formação superior}

A quinta pergunta do questionário abordou a formação em nível superior dos TPICs. As seguintes opções foram apresentadas aos respondentes: a) "Não tenho formação superior"; b) Letras; c) Direito; d) Engenharias; e) Ciências Sociais; f) Ciências Econômicas e g) "Outras". Para a última opção, havia a possibilidade de os respondentes escreverem expressamente o nome das áreas em que haviam obtido um diploma de nível superior. Os respondentes poderiam marcar mais de uma opção. Ao responderem, 9,1\% dos sujeitos da pesquisa afirmaram não ter formação superior; $57,6 \%$ afirmaram ter formação em Letras; $12,1 \%$, em Direito; 0\%, em Engenharias; $12,1 \%$, em Ciências Sociais; $6,1 \%$, em Ciências Econômicas; e 27,3\%, em Outras (Linguística Geral e Aplicada; Ciências Contábeis; Fisioterapia; Ciências Humanas/Biológicas: Psicologia; História; Turismo; Língua Francesa; Comunicação Social; Pedagogia e Orientação Educacional).

A partir dessa amostra, depreende-se que a maioria dos tradutores possui formação superior em Letras, o que parece natural, já que este curso superior normalmente está diretamente relacionado a línguas estrangeiras, embora na maioria das vezes não consista, aqui no Brasil, 
necessariamente em um curso de bacharelado ou habilitação específica em tradução. Essa percentagem pode inclusive ser mais elevada, levando-se em conta que alguns respondentes, ao escolherem a opção "Outros" e ali mencionarem cursos como Linguística Geral e Aplicada ou Língua Francesa, na verdade também se formaram em cursos superiores inseridos, de forma prática, na área de Letras. Observa-se também uma quantidade significativa de profissionais de outras áreas do conhecimento (Direito: 12,1\%; Ciências Sociais: 12,1\%; Outras: $27,3 \%$ ), o que nos permite inferir que a falta de requisitos para a formação em tradução/interpretação parece estimular o ingresso de profissionais de outras áreas no ofício de TPICS.

\subsubsection{Formação acadêmica em tradução}

A sexta questão indagava se os TPICs possuem formação acadêmica em tradução ou não. Como resposta, 21,2\% dos entrevistados afirmaram que sim, e 78,8\%, que não. Tal resposta provavelmente se deve ao fato de não haver formação acadêmica nessa área específica no Ceará até um período recente. Tal fato dificultava, aos profissionais em questão, o acesso à formação acadêmica, já que seria necessário viajar para outros estados ou países para realizar, por exemplo, uma pós-graduação em Estudos da Tradução. Em 2014, foi criada a Pós-Graduação em Estudos da Tradução (POET) na Universidade Federal do Ceará (UFC), sendo a primeira do gênero na região Norte-Nordeste do Brasil. Também é relevante salientar que em 1995 já fora criado, no Departamento de Letras Estrangeiras (DLE) da UFC, o Curso de Especialização em Tradução de Alemão, Francês e Inglês, no âmbito do qual foram formadas duas turmas. Em 2009, o mesmo DLE lançou um novo curso de pós-graduação lato sensu, desta vez intitulado Curso de Especialização em Estudos da Tradução, e também tendo sido formadas duas turmas. Outrossim, a Universidade Estadual do Ceará (UECE) ofertou três turmas do Curso de Especialização em Tradução no período de 2011 a 2014.

\subsubsection{Nível da formação em tradução}

A sétima pergunta não foi considerada obrigatória e referia-se apenas aos tradutores que responderam à sexta pergunta afirmativamente, indagando qual o nível da formação superior em tradução dos participantes, que poderiam assinalar mais de uma opção. Dentre os respondentes, $14,3 \%$ afirmaram ter curso de Graduação na área; $71,4 \%$, curso de Especialização; e 14,3\%, Mestrado em (Estudos da) Tradução.

Como já mencionado no item anterior, no Estado do Ceará foram realizados apenas poucos cursos de especialização na área de tradução e por um breve espaço de tempo, além de atualmente haver apenas um programa de mestrado específico, que teve início em 2014. Isso certamente pode ser entendido como um entrave para que alguns dos respondentes tivessem acesso a uma formação acadêmica na área de tradução e/ou interpretação no Ceará. Entendemos que, se um maior número de respondentes afirma ter o título de especialistas em tradução, isso provavelmente se deve ao fato de terem usufruído desses cursos de especialização que foram oferecidos nas duas universidades cearenses mencionadas. Todavia, também não se pode excluir a possibilidade de alguém ter feito sua formação em tradução independentemente do nível - em outro estado brasileiro ou mesmo no exterior.

\subsubsection{Formação acadêmica em interpretação}

$\mathrm{O}$ alvo da oitava questão era saber se o público-alvo do questionário possui formação em interpretação. Ao serem indagados sobre essa 
questão, 18,2\% afirmaram ter formação na área, e $81,8 \%$, não. A apreciação desses dados permite concluir que a ausência de cursos na área de interpretação no Ceará dificulta o acesso dos TPICs (ou candidatos ao ofício) a essa qualificação, visto que os cursos de pós-graduação lato sensu e o mestrado acadêmico supracitados são em Estudos na Tradução. Não há, portanto, um curso de pós-graduação voltado especificamente para uma formação em interpretação. Essa resposta comprova a hipótese de que os TPICs do Ceará em geral não têm formação em interpretação. Observe-se que essa pergunta cumpria seu objetivo, mas ainda não deixava claro de que tipo de formação se trataria, já que esse tema só seria desenvolvido na próxima questão.

\subsubsection{Nível da formação em interpretação}

A nona questão tinha relação direta com a anterior e foi respondida apenas pelos participantes que haviam dado uma resposta afirmativa à questão 8 . Os respondentes podiam assinalar mais de uma alternativa, caso isso se aplicasse à sua respectiva realidade. Ao serem questionados sobre o nível da formação em interpretação, 16,7\% afirmaram ter curso de Graduação na área; 66,7\%, curso de Especialização; 16,7\%, Mestrado; 0\%, Doutoramento; e $0 \%$, Pós-Doutorado.

Os dados obtidos permitem inferir que, no tocante à formação acadêmica em interpretação, há mais respondentes com curso de especialização em interpretação. A ausência de profissionais com doutorado e pós-doutorado nessa área justifica-se pelo fato de serem raros no Brasil, e inclusive em outros países, os cursos de doutorado e pós-doutorado com linhas de pesquisa específicas na área de interpretação. Como os respondentes não foram indagados sobre o local em que fizeram sua formação em interpretação nem sobre o nome do curso frequentado, somente foi possível especular que, no caso dos cursos de pós-graduação lato sensu, pode ter-se tratado de alguma disciplina de interpretação inserida no currículo de algum Curso de Especialização em Tradução/ Estudos da Tradução ou algum outro curso congênere. A mesma afirmação poderia valer também para cursos de graduação e mestrado. Outra possibilidade é que tenham feito seus cursos fora do Brasil, já que nosso país oferece pouquíssimos cursos de formação de intérpretes.

\subsubsection{Modalidades-alvo da formação em interpretação}

$\mathrm{Na}$ décima questão, abordavam-se as modalidades de interpretação estudadas pelos TPICS em sua formação. Quatro alternativas foram propostas: a) interpretação simultânea; b) interpretação consecutiva; c) interpretação sussurrada; e d) interpretação de negociações. Os informantes podiam marcar mais de uma alternativa. Observou-se que $71,4 \%$ dos respondentes assinalaram a primeira modalidade; $100 \%$, a segunda; $57,1 \%$, a terceira; e $28,6 \%$, a quarta.

A análise desses dados permite concluir que interpretação consecutiva foi a modalidade mais indicada pelos respondentes, correspondendo a $100 \%$ dos que responderam afirmativamente à questão 9. Não é de se estranhar que a modalidade apontada com mais frequência tenha sido justamente a interpretação consecutiva, já que ainda é muito utilizada em diferentes contextos de interpretação no Ceará. Ademais, tal modalidade prescinde de aparatos técnicos - normalmente caros -, como os exigidos pela interpretação simultânea. Esclareça-se, aqui, que a interpretação sussurrada, por sua vez, embora tenha largo emprego em eventos em que normalmente apenas uma 
ou duas pessoas necessitem de interpretação simultânea e sem cabine, normalmente não é treinada em cursos de formação. Estranhou-se que a interpretação de negociações não tenha sido citada com grande frequência, já que esta, se comparada à interpretação consecutiva, prescinde do estudo e uso da técnica de tomada de notas. $\mathrm{Na}$ interpretação consecutiva propriamente dita, o intérprete normalmente precisa do suporte das anotações em pequenos blocos que lhe permitam compreender, assimilar e em seguida reverbalizar blocos mais longos de ideias.

\subsubsection{Exercício da função de intérprete como TPIC}

$\mathrm{Na}$ questão 11, os respondentes foram questionados sobre o fato de já terem exercido a função de intérprete em uma das modalidades mencionadas na questão anterior. Os resultados obtidos apontam que $75,8 \%$ afirmaram que sim, e $24,2 \%$, que não. A amostragem das respostas permite deduzir que a prática da interpretação é frequente no exercício da função, visto que um número considerável foi revelado a partir do feedback dos respondentes, demonstrando que o conhecimento da prática pode ser considerado relevante para o exercício do cargo.

\subsubsection{Locais de atuação como TPIC}

A décima segunda questão referia-se aos locais em que os respondentes normalmente atuam - ou já atuaram - como intérpretes. Os respondentes podiam marcar mais de uma alternativa. Constatou-se que $40 \%$ afirmaram ter realizado o ofício da interpretação em tribunais; $16 \%$, em cartórios de paz; 40\%, em cartórios de registro civil; $24 \%$, em tabelionatos; $24 \%$, em cartórios de imóveis; $8 \%$, em hospitais; $8 \%$, em igrejas; $20 \%$, na Polícia Federal; $4 \%$, em penitenciárias; $16 \%$, em órgãos da admi- nistração pública; 44\%, em empresas privadas; $24 \%$, em portos; $0 \%$, em aeroportos; $48 \%$, em congressos/conferências; e $28 \%$, em "outros" (visitas oficiais, pesquisas de campo, capitania dos portos, universidades, reuniões em escritórios de advocacia, assembleias de condomínio, transportes urbanos, processamento de dados, reuniões de reitores brasileiros, missões acadêmicas). Cumpre destacar que, como aqui havia a possibilidade de múltipla escolha, um mesmo respondente pode ter marcado todas as opções disponíveis e inclusive ter adicionado outros segmentos na opção "outros".

A análise desses dados permite observar que os contextos com os quais os respondentes se deparam com mais frequência em suas práticas profissionais são congressos/conferências, empresas privadas, tribunais e cartórios de registro civil, seguidos por "outros", tabelionatos, cartórios de imóveis, Polícia Federal, órgãos da administração pública, cartórios de paz, hospitais, igrejas e penitenciárias. Nenhum respondente afirmou ter realizado o exercício da interpretação em aeroportos.

\subsubsection{Importância da formação em interpretação para a realização da função}

$\mathrm{Na}$ décima terceira questão, solicitava-se aos respondentes que se posicionassem com relação à seguinte afirmação: "A formação em interpretação é um componente essencial para a realização da minha função de TPIC". Verificaram-se estas respostas: $6,1 \%$ declararam concordar totalmente; $51,5 \%$ concordaram; $3 \%$ mostraram-se indecisos; $30,3 \%$ discordaram; e $9,1 \%$ discordaram totalmente.

A aferição dos dados coletados permite inferir que a maioria dos respondentes considera a formação em interpretação essencial para o exercício da função, ainda que haja um percentual considerável de respostas que discor- 
dam dessa afirmação. Tal número relaciona-se diretamente às respostas obtidas nas questões 11 e 12 , em que a maioria dos respondentes declarou já ter atuado como intérprete no exercício da função e nos diversos contextos apresentados.

Fazendo-se uma correlação entre esses dados obtidos e o duplo título conferido ao ofício em questão - Tradutor Público e Intérprete Comercial -, também podemos teorizar sobre os motivos da existência dessa larga faixa (30,3\% $+9,1 \%$ ) de respondentes que não veem como essencial uma formação em interpretação. Por um lado, talvez eles se apoiem nas instruções do próprio Decreto $\mathrm{n}^{\mathrm{o}} 13.609$, de 21 de outubro de 1943. Nas disposições ali contidas, em nenhum momento se exige qualquer tipo de formação em interpretação e, na verdade, sequer em tradução.

\subsubsection{Obstáculos e restrições impostos à atuação dos "intérpretes comerciais"}

A décima quarta pergunta propunha aos profissionais uma reflexão sobre os fatores que constituem empecilhos para suas atuações como intérpretes comerciais. Os respondentes podiam marcar mais de uma opção, caso isso se aplicasse às suas realidades. Em resposta a essa questão, 9,1\% apontaram como obstáculo "a minha total falta de conhecimento e prática nesta área"; 48,5\%, "a pouca prática que tenho com essa atividade"; $18,32 \%$, "a incerteza sobre o pagamento do trabalho realizado"; $27,3 \%$, "a necessidade de deslocar-me para a realização do trabalho"; 69,7\%, "a grande variedade temática a que estou sujeito"; 39,4\%,"a situação de estresse a que me submeterei durante o trabalho"; e 15,2\%, "Outros". No espaço existente ao lado dessa última opção, constataram-se estas explicações acrescentadas por alguns dos respondentes: "falta de informações prévias sobre o cliente e seu objetivo"; "a insegurança em falar e compreender a língua estrangeira 'quase' como se fosse sua língua materna"; "demanda de tempo durante dias úteis e fins de semana"; "A pergunta é genérica mas as respostas são formuladas na primeira pessoa. Respondendo de forma genérica, eu marcaria as opções 1 , 2, 6." "Pouca disponibilidade de tempo."

Fazendo-se a devida leitura dos dados obtidos, é possível inferir que, para os respondentes, o maior obstáculo para suas atuações é a grande variedade temática a que estão sujeitos, seguida da pouca prática que têm na área de interpretação. Por ser uma atividade que não admite o critério da corrigibilidade com a mesma facilidade que a tradução, talvez muitos TPICs, por não terem formação específica na área nem prática suficiente como intérpretes, acabem temendo enfrentar situações de interpretação, em que são normalmente surpreendidos com os temas mais variados. Juntos, estes fatores certamente causam situações "de estresse", como deixa claro o percentual de $39,4 \%$ que coube a esse item.

\subsection{Formação em interpretação para TPICS}

Diante dos resultados obtidos, estamos cônscios de que se faz mister a existência de algum tipo de curso que permita uma formação prática e/ou teórico-prática na área de interpretação para TPICs. Como no Estado do Ceará ainda não há cursos de graduação que formem tradutores e intérpretes, espera-se que as IES supracitadas continuem a oferecer cursos em nível de especialização e mestrado, mas que também se empenhem em oferecer, no mínimo, módulos de interpretação. Sabe-se, todavia, que o mestrado em Estudos da Tradução oferecido na UFC é de cunho marcadamente teórico. Um curso de especialização ou mesmo de extensão - como formação continua$\mathrm{da}$ - que se destine a promover uma formação 
mais prática deverá, na nossa opinião, seguir estas orientações de Pagura (2015, p. 201202), que ressaltam as diferenças entre tradução e interpretação:

Considerando-se as reflexões teóricas brevemente discutidas acima, não é difícil propormos algumas questões de natureza prática relacionadas à formação de intérpretes. A primeira delas é de que o currículo de um curso para a formação de intérpretes deve ser diferente do oferecido para a formação de tradutores. Considerando-se as diferenças já mencionadas antes, não é concebível que se pretenda formar intérpretes e tradutores a partir de um currículo único. Desnecessário dizer, a formação de intérpretes deve ser feita no âmbito da oralidade - exercícios escritos encontram muito pouca justificativa para o processo. Como condição prévia para admissão a um programa de formação de intérpretes, o candidato deverá sempre demonstrar bom domínio da língua materna e de uma ou mais línguas estrangeiras, sempre em suas variantes orais, dependendo de como se organize o programa.

O exercício da prática da oralidade, como proposto acima por Pagura, é uma condição sine qua non para que os TPICs se familiarizem com as situações de interpretação em que normalmente se verão envolvidos. Acresçam-se ainda os conhecimentos específicos que deverão ser adquiridos e treinados em situações pedagógicas que imitem situações específicas do cotidiano de TPICs (ida a cartórios, audiências na Polícia Federal, interrogatórios na polícia ou em juízo, casamentos civis etc.). De forma genérica, ou seja, como recomendação válida para cursos de formação de intérpretes em geral, Lauterbach (1996, p. 204s) faz algumas sugestões que consideramos igualmente úteis para o caso específico de formação em interpretação aqui abordado:

No programa inicial do curso [de Interpretação], deverão estar incluídos exercícios voltados para o treinamento da memória e exercícios de tradução direta. Sugere-se que, em seguida, proceda-se aos exercícios de interpretação simultânea. O objetivo dos exercícios deverá ser a simulação de situações reais de interpretação. Recomenda-se uma progressão tal em que o grau de dificuldade possa aumentar paulatinamente no tocante à duração, à temática, aos gêneros textuais utilizados, à velocidade do palestrante, ao número de interlocutores envolvidos e à especificidade das situações em que atuará o intérprete.

Acreditamos que um programa de formação que insista em situações e contextos práticos de interpretação, especialmente com a utilização de materiais autênticos, ajudará de modo fundamental a treinar TPICs interessados em atuar, com maior desenvoltura e precisão, como intérpretes. Não se podem esquecer outros aspectos que também precisam ser incluídos em uma formação dessa natureza, tais como: a) conhecer e dominar uma técnica de tomada de notas para interpretação consecutiva; b) ser capaz de formar listas de vocabulário/glossários para usar em situações urgentes de interpretação; c) treinar o ouvido para diferentes sotaques das línguas de trabalho; d) familiarizar-se com a interpretação intermitente e a sussurrada, para além das modalidades mais comumente usadas.

\section{Considerações finais}

$\mathrm{Na}$ abertura deste parágrafo conclusivo gostaríamos de mencionar, em primeiro plano, alguns dados demográficos não abordados nas seções anteriores deste artigo: a) 81,8\% dos respondentes atuam como TPIC há quatro anos; b) $57,6 \%$ dos respondentes declararam-se do gênero masculino; c) $33,3 \%$ dos respondentes tinham entre 41 e 50 anos; d) $60,6 \%$ dos respondentes afirmaram ter o inglês como língua de trabalho. Em relação às respostas abordadas de forma específica neste artigo, reiteramos: a) $57,6 \%$ dos respondentes têm formação superior em Letras; b) 78,8\% não têm formação acadêmica em tradução; c) com relação aos que responderam "sim" à formação acadêmica 
em tradução, 71,4\% dos respondentes têm curso de especialização; d) $81,8 \%$ dos respondentes não têm formação acadêmica em interpretação; e) dentre os que responderam "sim" à formação acadêmica em interpretação, 66,7\% possuem especialização na área; f) dentre os que responderam afirmativamente à questão referente à formação acadêmica em interpretação, $100 \%$ receberam treinamento em interpretação consecutiva, seguida de simultânea $(71,4 \%)$, sussurrada $(57,1 \%)$ e de negociações (28,6\%); g) 75,8\% afirmaram já ter exercido a função de intérprete em uma das modalidades mencionadas anteriormente; h) no tocante aos locais em que os respondentes já atuaram como TPICs, $48 \%$ afirmaram ter atuado em congressos/conferências, $44 \%$, em empresas privadas, e $40 \%$, em tribunais e em cartórios de registro civil; i) quanto à pergunta: "A formação em interpretação é um componente essencial para a realização da minha função de тPIC", 51,5\% dos respondentes assinalaram "concordo", e 6,1\% declararam concordar totalmente; j) no que concerne aos obstáculos que podem limitar/prejudicar a atuação do intérprete comercial, 69,7\% dos respondentes declararam "a grande variedade temática a que estarei sujeito(a)", seguido por "A pouca prática que tenho com essa atividade"(48,5\%).

A aferição dos dados coletados permitiu-nos constatar que, apesar de a maior parte dos TPIcs do Ceará ter formação em Letras, correspondendo a $57,6 \%$ dos respondentes, a maioria não possui perfil acadêmico em tradução $(78,8 \%)$ e em interpretação $(81,8 \%)$, o que se reflete, como podemos concluir, na necessidade de treinamento/formação, visando a uma atuação prática de TPICs com maior segurança teórico-prática.

Outro aspecto digno de nota foi a dificuldade de acesso a informações sobre a história dos TPICs no Ceará, inclusive na própria Junta Co- mercial do Estado do Ceará. Cremos que tal fato deva constituir-se em um incentivo para que futuras pesquisas tentem trazer a lume um panorama histórico sobre a atuação dos TPICs no Ceará.

Uma vez que a maioria dos TPICs do Estado do Ceará não possui formação em interpretação, como atestaram as respostas obtidas em nossa pesquisa, podemos depreender que os TPICs adquirem as habilidades para realizar as diversas modalidades de interpretação predominantemente através da prática. Tal fato sinaliza uma questão problemática, visto que a atividade da interpretação, além de exigir competência linguístico-cultural, é altamente complexa e requer treinamento e prática constantes. Além disso, é pertinente ressaltar que uma atuação como intérprete realizada de forma inadequada pode interferir diretamente nos destinos das pessoas que solicitam o serviço ou que dependem da interpretação, como é o caso da interpretação de tribunal realizada em audiências, interrogatórios, julgamentos etc. Entendemos ainda ser necessária a aplicação de duas medidas mais urgentes, com vistas a tentar mudar a situação dos TPICs do Estado do Ceará analisada neste trabalho, que talvez também encontre paralelos em outras unidades federativas do Brasil. Primeiramente, deveria ser repensada a estrutura das provas orais concebidas para os concursos de provimento de novos tPICs. Em vez de se realizar apenas a avaliação da performance na modalidade de tradução oral à prima vista nas duas direções, como foi feito no último concurso realizado no Ceará em 2011 (e como também tem ocorrido na maioria dos concursos realizados em outros Juntas Comerciais do Brasil), poderia ser aferido o desempenho dos candidatos nas diferentes modalidades de interpretação (interpretação simultânea, consecutiva e sussurrada), além da tradução oral à prima vista, já presente no formato atual. $\mathrm{O}$ acréscimo dos outros modos 
de trabalho possibilitaria verificar e avaliar a aptidão dos candidatos em realizar a atividade interpretativa utilizando-se das diversas modalidades de interpretação. Tal medida não apenas implicaria no ingresso dos candidatos que possuíssem essa aptidão, como incentivaria os interessados no concurso a buscarem formação na área. Em segundo lugar, como forma de proporcionar alguma formação básica e/ou continuada àqueles TPICs que não têm domínio teórico-prático de interpretação, seria recomendável algum tipo de parceria entre aquelas universidades que já ofertaram cursos de especialização na área de tradução e/ou interpretação - Universidade Federal do Ceará e a Universidade Estadual do Ceará - e a Junta Comercial do Estado do Ceará.

\section{Referências}

Aubert, F. H. (1988). Tipologia e procedimentos da tradução juramentada. Teoria, legislação, modelos e exercícios práticos [Apostila de estudos]. São Paulo: CITRAT.

Campbell, A. de S. (1984). Tradutores Públicos e Traduções Juramentadas no Brasil. Em W. M. Portinho (Org.), A tradução técnica e seus problemas (pp. 107-146). São Paulo: Álamo.

Decreto-lei $\mathrm{n}^{\mathrm{o}} 1.608$, de 18 de setembro de 1939. Código de Processo Civil (1939). (Disponívelem:http://www.planalto.gov. br/ccivil_03/Decreto-Lei/1937-1946/ Del1608.htm; acesso: 05/04/2019)

Decreto $\mathrm{n}^{\circ} 13.609$, de 21 de outubro de 1943. Aprova o regulamento do ofício de Tradutor Público e Intérprete Comercial no território da República, Diário Oficial da República Federativa do Brasil, Poder Executivo (1943) (Disponível em: http://www.planalto.gov.br/ccivil_03/decreto/1930-1949/ D13609.htm; acesso: 05/04/2019)

Decreto $\mathrm{n}^{\circ} 5.626$ de 22 de dezembro de 2005. Regulamenta a Lei $\mathrm{n}^{\circ} 10.436$, de 24 de abril de 2002, que dispõe sobre a Língua Brasileira de Sinais - Libras, e o art. 18 da Lei $\mathrm{n}^{\circ} 10.098$, de 19 de dezembro de 2000, Diário Oficial da República Federativa do Brasil (2005). (Disponível em http://www.planalto.gov.br/ccivil_03/_ ato2004-2006/2005/decreto/d5626.htm; acesso: 05/04/20019)

Hurtado Albir, A. (2013). Traducción y traductología. Introducción a la traductología. Madri: Cátedra.

Kade, O. (1968). Zufall und Gesetzmäßigkeit in der Übersetzung. Leipzig: Verlag Enzyklopädie.

Lauterbach, S. (1996). Übersetzen und Dolmetschen in Lateinamerika: Studienführer, Bibliographie und Modellcurriculum/Traducción y Interpretación en América Latina/Tradução e Interpretação na América Latina. Munique: iudicium verlag $\mathrm{GmbH}$. Lei $\mathrm{n}^{\mathrm{o}} 3.071$, de $1^{\mathrm{o}}$ de janeiro de 1916 . Código Civil dos Estados Unidos do Brasil (1916). (Disponível em: https://www2. camara.leg.br/legin/fed/lei/1910-1919/ 1ei-3071-1-janeiro-1916-397989-publicacaooriginal-1-pl.html; acesso: 05/04/2019)

Lei Presidencial $n^{\circ} 10.436$ de 24 de abril de 2002. Dispõe sobre a Língua Brasileira de Sinais - Libras e dá outras providências (2002). (Disponível em: http://www. planalto.gov.br/ccivil_03/LEIS/2002/ L10436.htm; acesso: 05/04/2019)

Mikkelson, H. (2009). Interpreting is interpreting - or is it? aiic.net. December 14, 2009. (Disponível em: https:// aiic.net/page/3356/interpreting-is-interpreting-or-is-it/lang/1; acesso em 05/04/2019)

Oliveira, L. E. M. (2005). As origens da profissão de tradutor público e intérprete comercial no Brasil (1808-1943). Claritas. Revista do Departamento de Inglês da Pontifícia Universidade Católica de São Paulo, 11 (2), 25-41. Disponível em: http://revistas. pucsp.br. Acesso em: 05/04/2019. 
Oliveira, L. E. M. (2006). A instituição do ensino das Linguas Vivas no Brasil: o caso da Língua Inglesa (1809-1890) [Tese de Doutorado]. Programa de Estudos Pós-Graduados em Educação: História, Política, Sociedade, PUC de São Paulo. (Disponível em http://www.sapientia.pucsp.br/tde_busca/arquivo.php?codArquivo $=2255$. Tde busca / arquivo.php? codArquivo $=2255$; acesso: 05/04/2019)

Pagura, R. (2001). Translation and interpretation - two sides of the same coin? Newsletter Braz-Tesol, (7), 10-13.

Pagura, R. J. (2010). A interpretação de conferências no Brasil: história de sua prática profissional e a formação de intérpretes brasileiros [Tese (Doutorado em Letras)]. Programa de Pós-Graduação em Estudos Linguísticos e Literários do Inglês, Universidade de São Paulo, São Paulo.

Pagura, R. J. (2015). Tradução \& interpretação. Em L. M. Amorim, C. C. Rodrigues e E. N. A. Stupiello (orgs.),
Tradução \& Interpretação: perspectivas teóricas e práticas (pp. 183-207). São Paulo: Cultura Acadêmica. (Disponível em: http://books.scielo.org/id/6vkk8/pdf/ amorim-9788568334614-09.pdf; acesso: 05/04/2019)

Pöchhacker, F. (2004). Introducing Interpreting Studies (pp. 9-26). London, Routledge.

Reiss, K. e Vermeer, H. J. (1991). Grundlegung einer allgemeinen Translationstheorie. Tübingen: Niemeyer.

Romão, T. L. C. (2014). A tomada de notas em interpretação consecutiva: algumas considerações históricas. TRADTERM, 24, 281-300.

Romão, T. L. C. (2015) Formação de intérpretes de línguas orais. Em V. de O. Pontes et. al. (eds.), A tradução e suas interfaces: múltiplas perspectivas. Curitiba: Editora CRV, 185-198.

Wyler, L. (2003) A tradução oral no Brasil. Em Linguas, poetas e bacharéis: uma crônica da tradução no Brasil (pp. 29-49). Rio de Janeiro: Rocco.

Cómo citar este artículo: Prata, A. B. A. y Romão, T. L. C. (2019). Formação de intérpretes versus ofício de tradutores públicos e intérpretes comerciais no Brasil: um estudo de caso no Estado do Ceará. Mutatis Mutandis. Revista Latinoamericana de Traducción, 12(1), 209-229. DoI: https://doi.org/10.17533/udea.mut. v12n1a08 